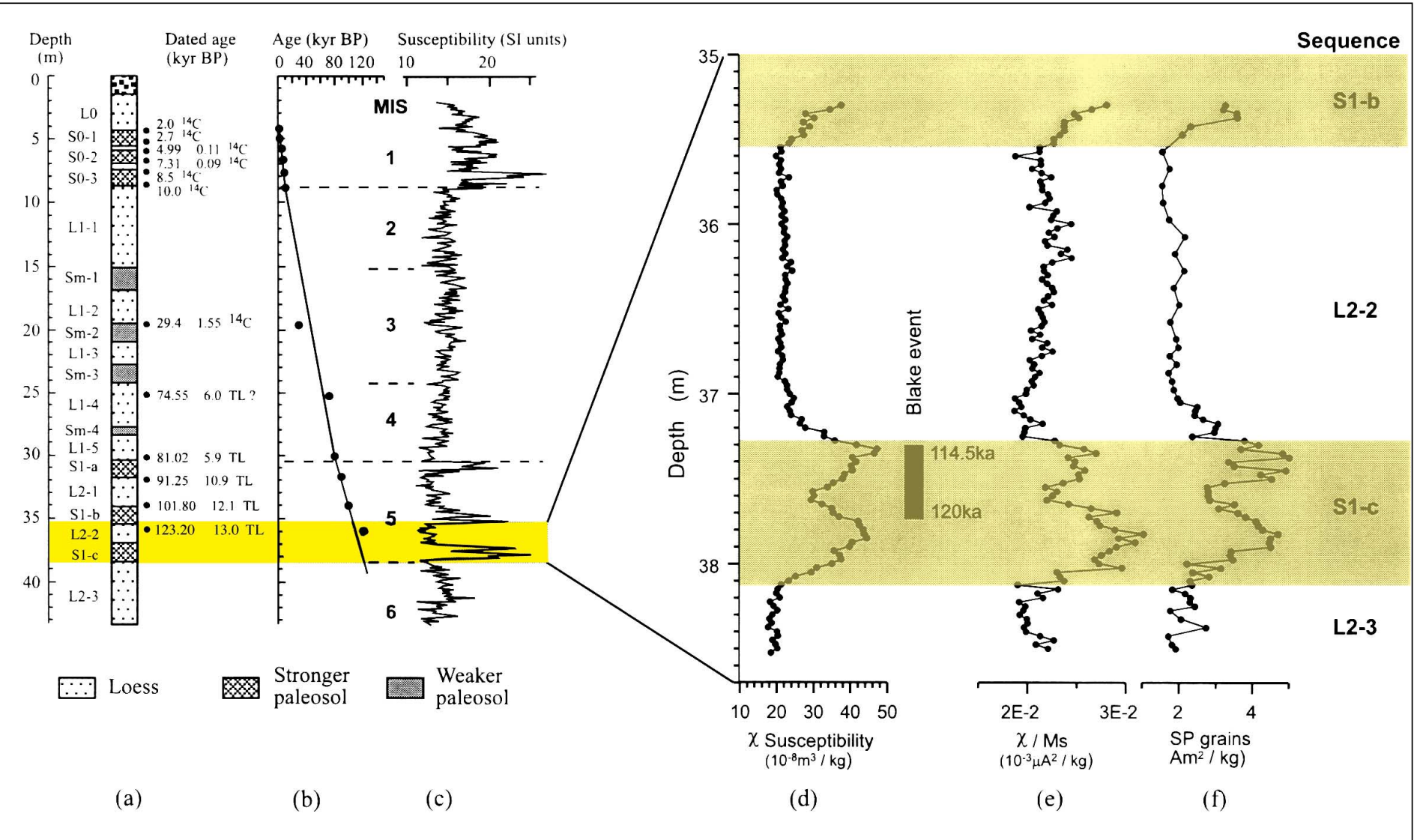

Fig. 9: Diagram showing the loess-paleosol sequence of the Jiuzhoutai well section (a) in Lanzhou on the western Loess Plateau, its age-depth relationship (b), volume magnetic susceptibility measured in the well (c), variations of mass-specific susceptibility $(\chi)(d), \chi /$ Ms (saturation magnetization) (e) and super paramagnetic (SP) grains measured on MPMS in the depth 35.3-38.5m. The black bar indicates the Blake event (Fang et al., 1997). Note the covariant changes of $x / M$ s and SP grains ( $f$ ) suggest that the summer monsoon experienced large amplitude and rapid changes during the Eemian interglacial (S1-c), which may correlate with oxygen isotope record of the GRIP ice core from Greenland (Dansgaard et al., 1993)

\title{
Last Interglacial sharp Monsoon Fluctuations: Rock Magnetic and Paleomagnetic Evidence from High Resolution Loess-Paleosol Sequence, Lanzhou, China
}

Climatic change during the last interglacial has become an important focus in global change research. Improved reconstructions may enhance our understanding of possible future climate change. Moreover, there are major uncertainties about the reliability of the apparent 'Eemian' instability recorded in Greenland ice cores (Dansgaard et al., 1993).

The western Loess Plateau contains the thickest loess deposits in the world. The combination of rapid, often continuous accumulation and weak pedogenesis (hence limited, post-accumulation overprinting by subsequent weathering), provides one of the best opportunities to reconstruct past monsoon climatic changes with high temporal resolution. This in turn points to the area as a crucial one for shedding light on climate variability during the Eemian, Isotope Stage 5e.

A late Pleistocene high-resolution loesspaleosol sequence has been obtained from a 40-m well dug in a loess section at Jiuzhoutai in the City of Lanzhou in the western Loess Plateau of China. The last interglacial interval consists of three individual paleosols marked downwards as S1-a, S1-b and S1-c separated by two loess layers L2-1 and L2-2 (Fig. 9a). Previous study has shown that paleosols S1a, S1-b and S1-c correlate with sub-stages 5a, $5 \mathrm{c}$ and $5 \mathrm{e}$ of marine isotope records (MIS), respectively (Fig. 9c). Samples were taken at 1$2.5 \mathrm{~cm}$ intervals for $\mathrm{S} 1$ series, yielding resolutions of c. 60-150 years per sample.

The Blake Event was found in the paleomagnetic record at the boundary between loess L2-2 and paleosol S1-c after thermal demagnetization and measurement on a $2 \mathrm{G}$ magnetometer. This provides an age estimation of 119.97 - 114.47 kyr BP for this part of sequence (Fig. 9d), in good agreement with TL-dates (Fang et al., 1997) (Fig. 9b).

Super-paramagnetic (SP) or ultra-fine (mainly $<0.03 \mu \mathrm{m}$ ) grains have been shown to have a pedogenic origin and are highly sensitive to climatic change, thus providing a powerful tool to reveal summer monsoon. Direct measure of SP grains on MPMS by thermal decay of low temperature isothermal remanence (Fig. 9f) accords well with estimates from saturation-magnetization (Ms)-normalized mass-specific susceptibility (Fig. 9e) for the studied section. Both show that SP grains are much more abundant in paleosols than in loess and reach highest values in S1-c (Figs. 9e and f). However, within S1-c large fluctuations in SP grain content are evident, characterized by three sharp peaks lasting ca. 1-3 kyr and culminating at about $128 \mathrm{kyr}, 118 \mathrm{kyr}$ and 116 kyr. The amplitude of the second of these fluctuations, lasting about $4 \mathrm{kyr}$, reaches ca. 75 percent of the full range of variation between paleosol peak and loess values and (Figs. 9d-f). These results suggest that the Asian summer monsoon experienced significant climatic changes during the Eemian Interglacial (MIS 5e), in good agreement with previous conclusion derived from nonmagnetic indicators (Fang et al., 1996).

\section{XiaO-Min Fang, Ji-Jun L}

Department of Geography, Lanzhou University, Lanzhou, Gansu 730000, China

\section{Subir BanerJee}

Institute for Rock Magnetism, University of Minnesota, Minneapolis, MN55455-0128, USA

\section{Rob Van der Voo}

Department of Geological Sciences, the University of Michigan, Ann Arbor, Ml 48109-1063, USA 